\title{
A new lesser metatarsophalangeal joint replacement arthroplasty design - in vitro and cadaver studies
}

\author{
Nikiforos P. Saragas ${ }^{1,2}$ (D) Paulo N. F. Ferrao ${ }^{1,2}$ (D) and Andrew Strydom ${ }^{3^{*}}$ (D)
}

\begin{abstract}
Background: Isolated degenerative joint disease and/or Freiberg's infraction of the lesser metatarsophalangeal joint, although not frequent may become debilitating in the younger individual. Currently, once conservative management fails, the mainstay of treatment is debridement and excision-interposition arthroplasty. Replacement arthroplasty has been ineffective in the long term as the joints are subject to severe repetitive fatigue loading over small articulating surfaces through a wide range of motion. This is an in vitro and cadaver study of a new design replacement arthroplasty developed by the senior author.

The aim of this study is to evaluate this novel replacement arthroplasty of the lesser metatarsophalangeal joint in a laboratory setting and cadaver implantation.

Methods: This three-component mobile bearing device is made of titanium and high density polyethylene which evolved over 4 years. It was subjected to 5,000,000 cycles in a laboratory under physiological and excessive forces to assess resistance to fatigue failure and wear pattern of the polyethylene liner. Following these tests, it was implanted in 15 fresh frozen cadavers at various stages of its development, during which the surgical technique was perfected. Range of motion and stability was tested using custom made instrumentation in four cadavers. The implant was inserted in a further two cadavers by an independent foot and ankle surgeon to check reproducibility.

Results: The device showed almost no signs of wear or surface deformation under physiological forces. The surgical technique was found to be simple and reproducible in the cadaver trial.

The average dorsiflexion was $28.5^{\circ}$ and $28.9^{\circ}$ pre- and post-implant respectively. The average plantar flexion was $33.8^{\circ}$ and $20.8^{\circ}$ pre- and post- implant respectively. The joints were stable both pre- and post-operatively. Post-operative stability was objectively assessed for dorsal displacement and dorsiflexion using a $5 \mathrm{kgf}(49 \mathrm{~N})$ and was found to be excellent.

* Correspondence: drewstrydom@hotmail.com

${ }^{3}$ Netcare Sunninghill Hospital, Suite 3A, -2 Level, Westwing, Cnr Nanyuki \&

Witkoppen Road, Sunninghill, Johannesburg 2157, South Africa

Full list of author information is available at the end of the article

(C) The Author(s). 2021 Open Access This article is licensed under a Creative Commons Attribution 4.0 International License, which permits use, sharing, adaptation, distribution and reproduction in any medium or format, as long as you give appropriate credit to the original author(s) and the source, provide a link to the Creative Commons licence, and indicate if changes were made. The images or other third party material in this article are included in the article's Creative Commons licence, unless indicated otherwise in a credit line to the material. If material is not included in the article's Creative Commons licence and your intended use is not permitted by statutory regulation or exceeds the permitted use, you will need to obtain permission directly from the copyright holder. To view a copy of this licence, visit http://creativecommons.org/licenses/by/4.0/ The Creative Commons Public Domain Dedication waiver (http://creativecommons.org/publicdomain/zero/1.0/) applies to the data made available in this article, unless otherwise stated in a credit line to the data. 
(Continued from previous page)

Conclusion: This novel lesser metatarsophalangeal joint replacement arthroplasty has been developed as an option in the surgical treatment of symptomatic degenerative joint disease and/or Freiberg's infraction resistant to conservative treatment. The implant was found to be durable and resistant to wear in the laboratory testing. The cadaver studies have shown it to require minimal specialized instrumentation with good surgical reproducibility.

This proof of concept study is the basis for clinical trials.

Keywords: Lesser metatarsophalangeal joint, Replacement arthroplasty, New design, Freiberg's infraction, Arthritis, Cadaver studies

\section{Introduction}

Degenerative arthritis of the lesser metatarsophalangeal joint (LMTPJ) in the foot is a relatively uncommon condition as compared to the inflammatory arthritides. Often the arthritis is isolated to one joint and commonly due to previous trauma or Freiberg's infraction. This condition may become debilitating in the younger individual. There is a paucity of published information on alternative treatment options as far as arthroplasties are concerned when conservative therapies fail. Excisional and interpositional arthroplasties using various tissues have and are still being used as the main surgical treatment option [1-15].

Joint replacement arthroplasty has been used in the end stages of the disease [16]. Silicone [17-26], metal [17-29] and ceramic [30] LMTPJ replacement arthroplasty as well as osteochondral autograft transplantation [6] have been reported with mixed success.

Currently there is no effective replacement available. These joints are subject to severe repetitive fatigue loading over small articulating surfaces through a wide range of motion.

Most published series stem from the 1970's and 1980's [17-25]. The initial simple silicone spacers and silicone ball [26] without stems were improved by the addition of prongs to increase stability. The Swanson prosthesis, originally designed for the hand, has been used for the LMTPJs [17-25]. The Nicolle, the Calnam-Nicolle and the Niebauer-Cutter hinged prosthesis had been adapted for LMTPJ arthroplasty. The reported cases are too few and short term to make recommendations for their use $[18,24]$.

In a series by Cracchiolo, $31 \mathrm{~s}$ MTPJs in 28 patients were replaced by a double-stem silicone implant and a single-stem in one. Six of these patients had Freiberg's infraction. Severe subluxation or dislocation of the 2nd MTPJ was present in 26 of $32 \mathrm{ft}$. None of the Freiberg's infraction group had significant deformity. At an average follow-up of 37 months, a good subjective result was recorded in $63 \%$ and good with reservations in $25 \%$. Transfer metatarsalgia was a reported complication in both the reservation and failure groups [17].
Sgarlato has advocated the use of a double-stem silicone prosthetic implant in several difficult-to-treat conditions. He found it to be successful in older (over age 50 years) patients [22].

In a small cohort of patients with a short follow-up, Townshend and Greiss used a total ceramic arthroplasty for painful destructive disorders. Eight of nine patients reported good or excellent results at a mean follow-up of 23 months [30].

All results quoted were from studies with a small number of patients to make any strong argument for favoring any of the procedures described meaningless.

The objective of this study is to design an effective replacement arthroplasty of the second and third metatarsophalangeal joint for end stage arthritis or symptomatic Freiberg's infraction to add to the armamentarium of the foot and ankle surgeon. The authors hypothesize that the design of this implant will effectively simulate the lesser metatarsophalangeal joint in both laboratory setting and cadaver trials so as to follow with clinical trials.

\section{Materials and methods}

A novel implant was designed and developed by the senior author (NPS) (Fig. 1 - Lesser metatarsophalangeal joint implants).

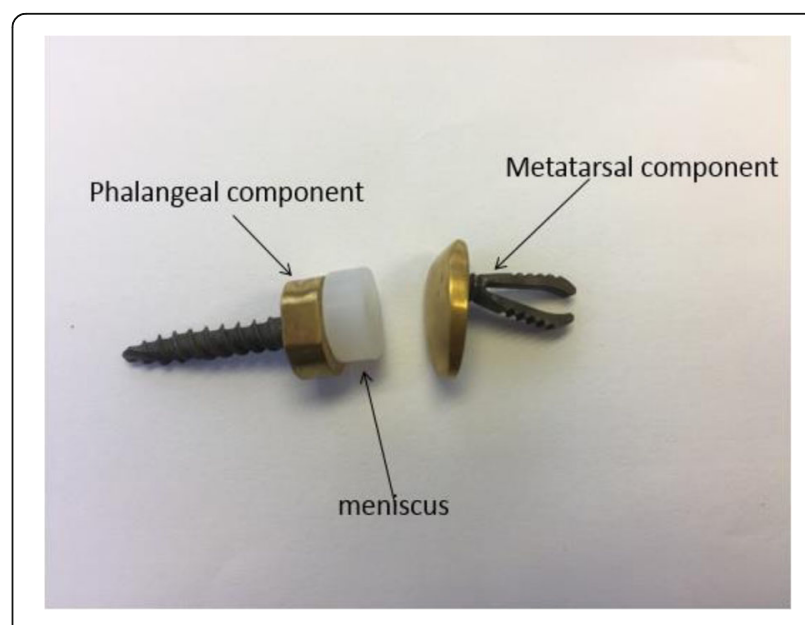

Fig. 1 Lesser metatarsophalangeal joint implants 
The implant is considered to be more of a resurfacing rather than a metatarsal head replacement so as not to interfere with the plantar condyles of the metatarsal head.

The implant can be visualized as a device permitting a stable yet mobile bearing unit.

The design was conceptualized as being low constrained with a high conformity that provides axial rotation and allowing more sagittal than coronal motion.

This new lesser metatarsophalangeal joint replacement is based on a three-component implant.

Although it is considered to be a three-component implant, the mobile bearing meniscus clips onto the phalangeal component via a peg which is smaller in diameter from the corresponding phalangeal socket allowing for multidirectional gliding at this interface, thus providing both stability and decreasing the torsional forces. The mobile bearing can rotate $360^{\circ}$.

The metallic components are made of titanium with a grid blasted under surface for maximum bony ingrowth. The articular surface has a titanium nitride finish for hardness. The meniscus is made of high-density polyethylene.

The implant allows for plantar and dorsiflexion with an element of medio-lateral translation and axial rotation. An integral part of the procedure is the soft tissue balancing of the joint. The plantar condyle is preserved with this implant so that the weight bearing status of the involved metatarsal will be maintained thus avoiding transfer lesions. The implant may be used as a total or hemi arthroplasty. The fixation is intramedullary (a novel "spring" fixation system for the metatarsal and a screw fixation for the phalangeal component) and the implant has high conformity and low constraint to withstand the stresses applied on it by walking and weight bearing, thus minimizing wear.

A number of implants of various sizes were manufactured for the purpose of the study. The sizes were determined by accurate skeletal measurements of the metatarsal heads and base of the proximal phalanges by using digital callipers. Forty adult skeleton feet were used as per the statistician's advice.

Female and male skeletons were included randomly from the anatomy department. The authors were concerned in creating a range of sizes that would accommodate both genders.

Radiographs of living subjects were used to measure the medullary diameter of the metatarsal and proximal phalanx. The $\mathrm{x}$-rays adhered to the international standard weight bearing protocol of foot $\mathrm{x}$-rays.

The combination of these parameters allowed the researchers to have a range of implant sizes manufactured

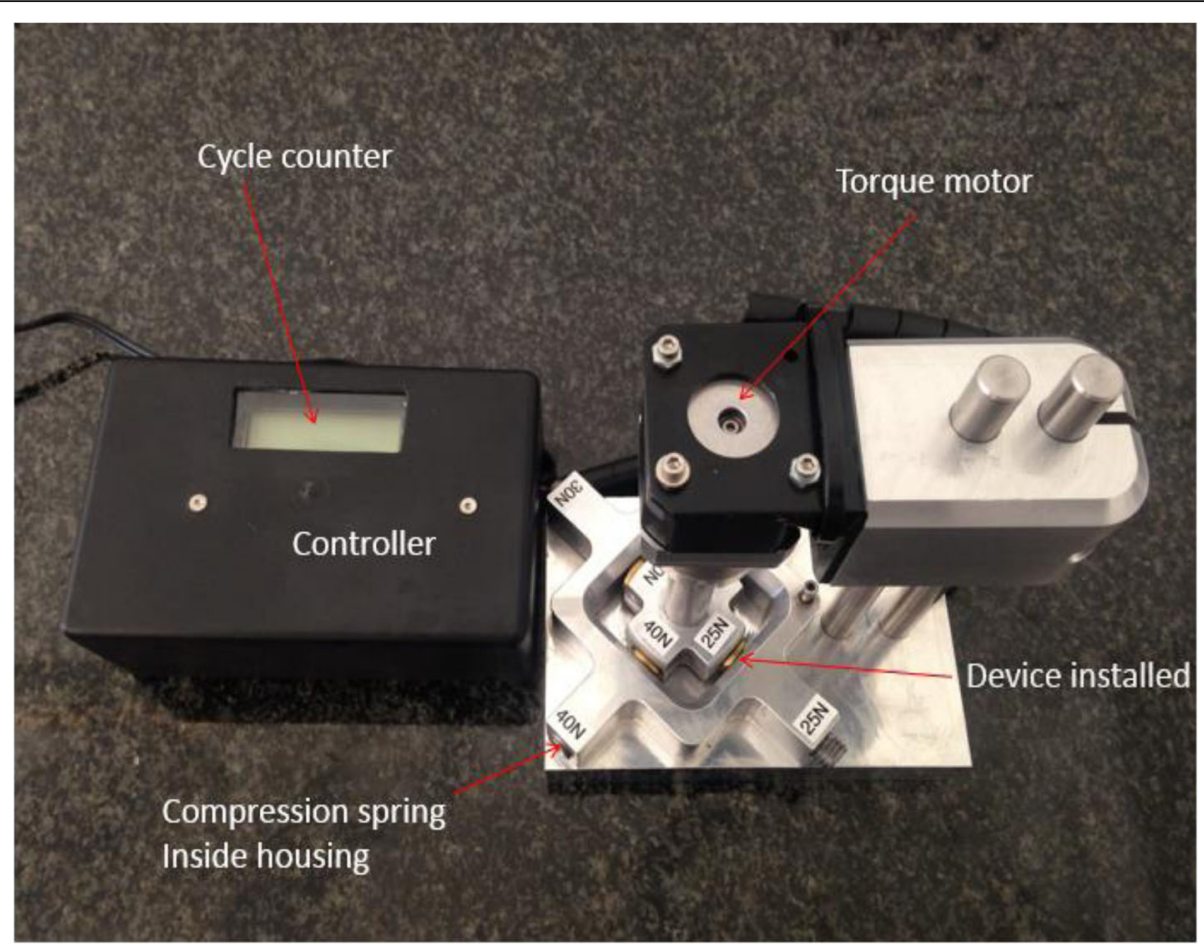

Fig. 2 Cyclical testing instrumentation - four stations 
for implanting into the cadavers. It was found that by using two phalangeal screw sizes, $98 \%$ of the adult population was accommodated.

\section{Cyclical testing in the laboratory}

For the purpose of testing this medical implant, a mechanical test apparatus was designed in conjunction with bioengineers and manufactured to simulate the articulation of the LMTPJ in the human foot. The apparatus incorporates four stations for testing four implants at different forces simultaneously (Fig. 2 Cyclical testing instrumentation - four stations). The compressive forces were applied during cyclic articulation by means of cylindrical helical silicone compression springs. The applied compression force was derived from the amount of deflection of the compression springs.

The articulation was generated using a $12-\mathrm{V}$ DC torsion motor capable of articulating each implant device to a pre-set angle at a frequency of $3 \mathrm{~Hz}$. Testing was conducted in de-ionized water in order to minimize any possible influence by the ions found in normal water. Each test station with its installed implants, was submerged in the de-ionized water (Fig. 3 - Cyclical testing instrumentation set-up). In addition, the test apparatus was covered for the duration of testing to prevent any foreign debris from entering the test environment.

In series one, four implants were tested. These implants were subjected to 5 million cycles each at physiological compressive forces of $3 \mathrm{~N}, 4 \mathrm{~N}, 6 \mathrm{~N}$ and $8 \mathrm{~N}$ respectively [31]. The implants were subjected to 5 million cycles, after which wear damage at the contact surface of each implant was captured by means of photographic imaging and thickness measurements of the meniscus. Measurements were

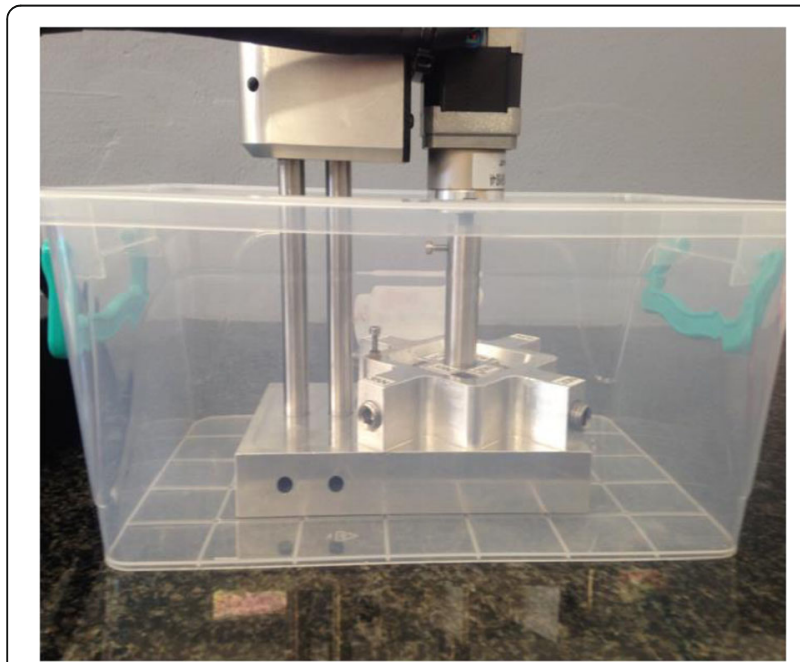

Fig. 3 Cyclical testing instrumentation set-up

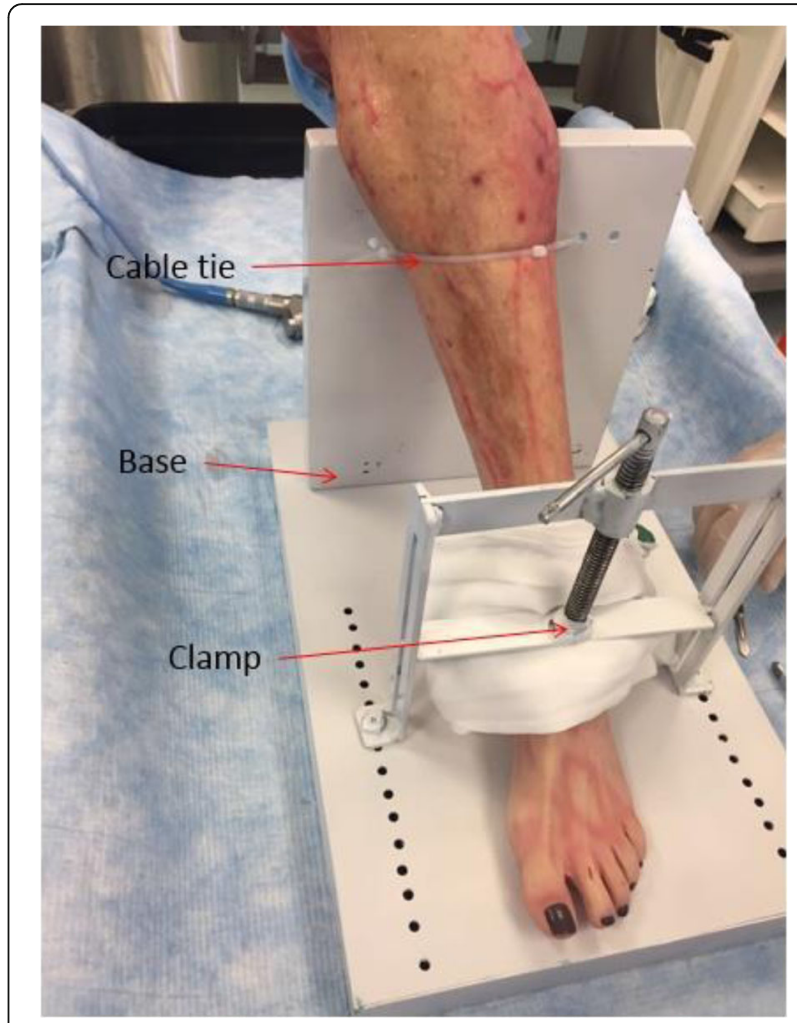

Fig. 4 Cadaver testing set up

carried out with a TESAMASTER Standard High Precision Micrometer with Digital Counter reading down to $1 \mu$ and the water was assessed for polyethylene particles.

In series two, four implants were subjected to excessive compressive forces of $25 \mathrm{~N}, 30 \mathrm{~N}, 35 \mathrm{~N}$ and $40 \mathrm{~N}$ respectively. Once again wear damage at the contact surface of each implant was captured and the water assessed for polyethylene particles.

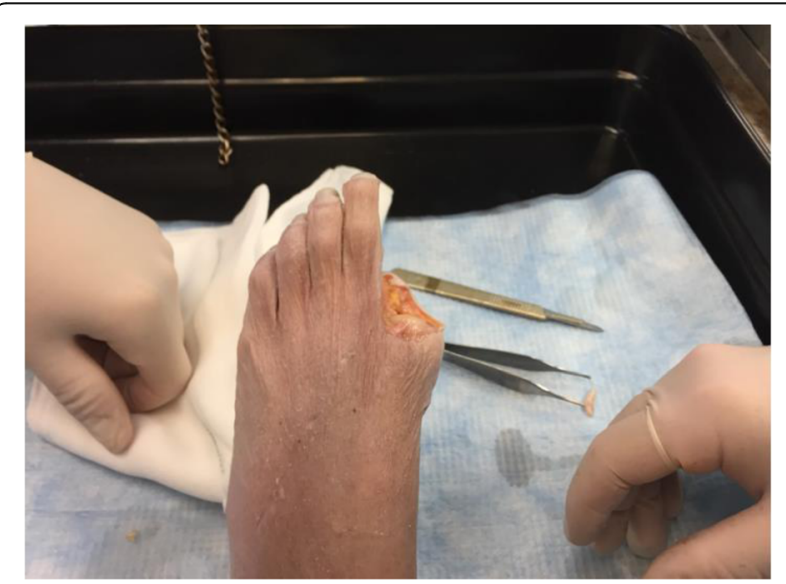

Fig. 5 Hallux disarticulation for application of electro-goniometer 


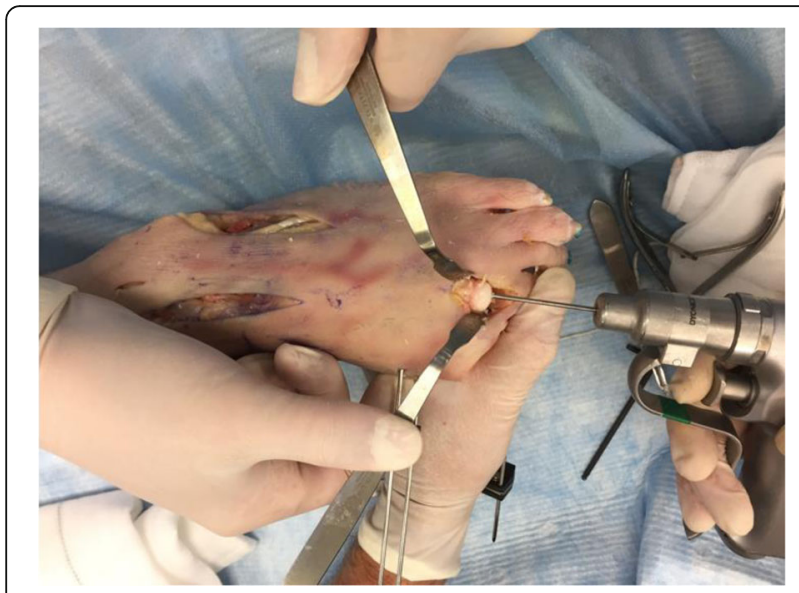

Fig. 6 Guide wire place in the metatarsal

\section{Cadaver trials}

During the evolution of the implant design, 15 cadavers were used over a period of 4 years. The cadaveric specimens were utilised as part of specialised foot and ankle training workshops run by the authors; the specimens were obtained through standard procurement processes with all necessary permissions.

At the final cadaver trial stage when the final product was tested, four cadavers (four toes) were used. After the fourth specimen, it was noted that all the measurements were remarkably similar and further specimens would prove to be unnecessary and unnecessarily expensive (Fig. 4 - Cadaver testing set up). Only the second metatarsophalangeal joint was tested. There were two male (specimens 1 and 3) and two female (specimens 2 and 4) cadavers.

A further two devices were then implanted in fresh frozen cadavers by an independent foot and ankle surgeon. Radiographs were obtained at this stage.

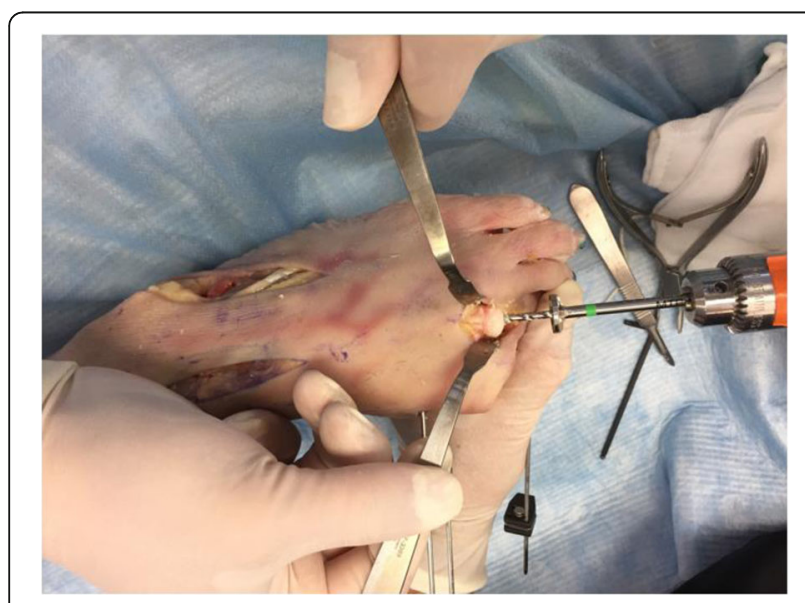

Fig. 7 Cannulated reamer over the guide wire

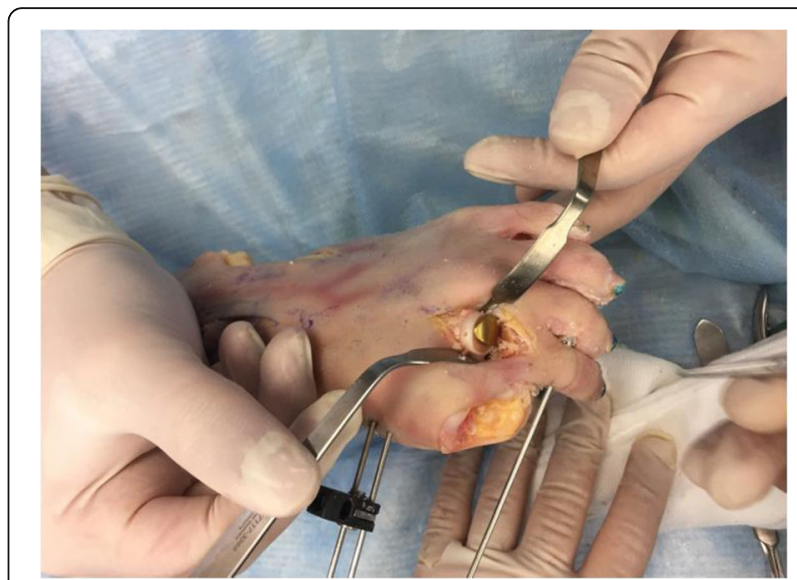

Fig. 8 Metatarsal component in place

\section{Surgical technique}

The hallux had to be disarticulated at the metatarsophalangeal joint (MTPJ) in order to accurately test the range of motion of the implanted device with a custom-made measuring tool (Fig. 5 Hallux disarticulation for application of electro-goniometer).

A dorsal longitudinal midline incision centred over the lesser metatarsophalangeal joint is made. The incision is deepened between the extensor digitorum longus and extensor digitorum brevis tendons down to capsule. The capsule is split longitudinally.

The collateral ligaments are dissected off the proximal phalanx. Three $\mathrm{mm}$ of the base of the proximal phalanx is excised using an oscillating saw and the proximal phalanx is hyper plantar flexed. More bone is excised as required in order to maximize range of motion. The plantar plate is left intact.

The edges of the metatarsal head is contoured by debridement of all osteophytes in order to restore a spherical head. A guide wire is driven into the metatarsal

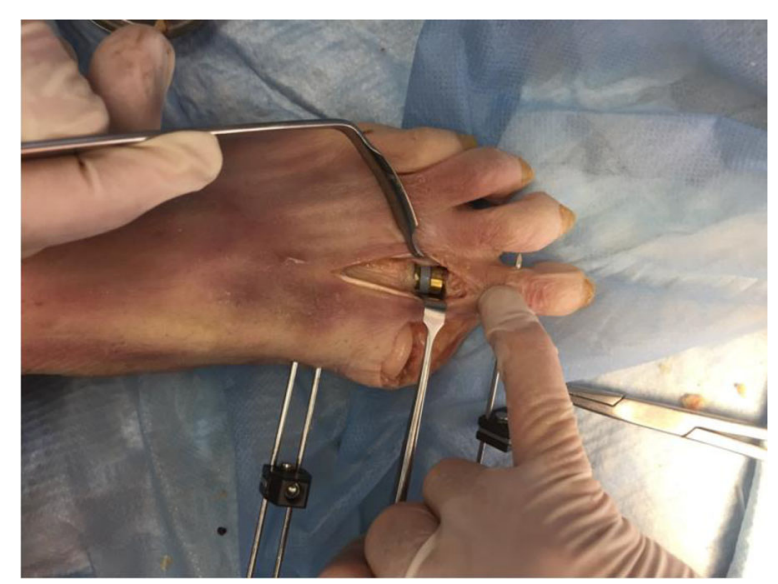

Fig. 9 Complete lesser metatarsophalangeal replacement in situ 

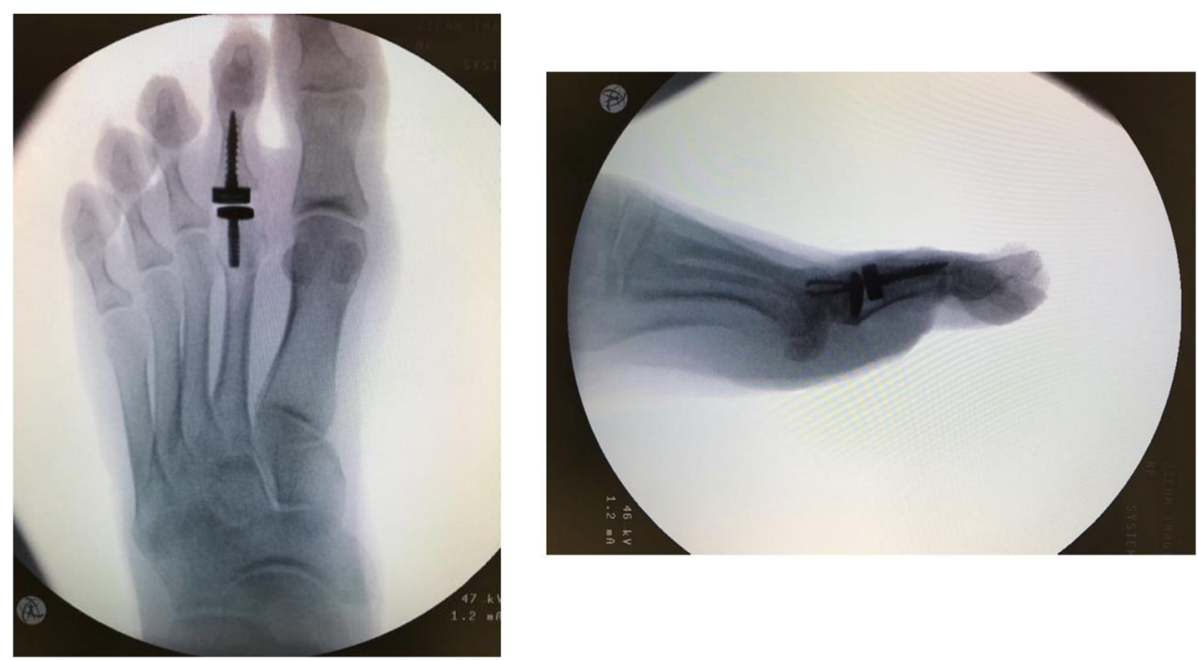

Fig. 10 Radiographic appearance of the implant (antero-posterior and lateral views)

head to centralize the component in the shaft (Fig. 6 Guide wire placement in the metatarsal). A cannulated reamer is then used to prepare the metatarsal head (Fig. 7 - Cannulated reamer over the guide wire). The metatarsal component is then inserted into the metatarsal head and gently impacted in place (Fig. 8 -

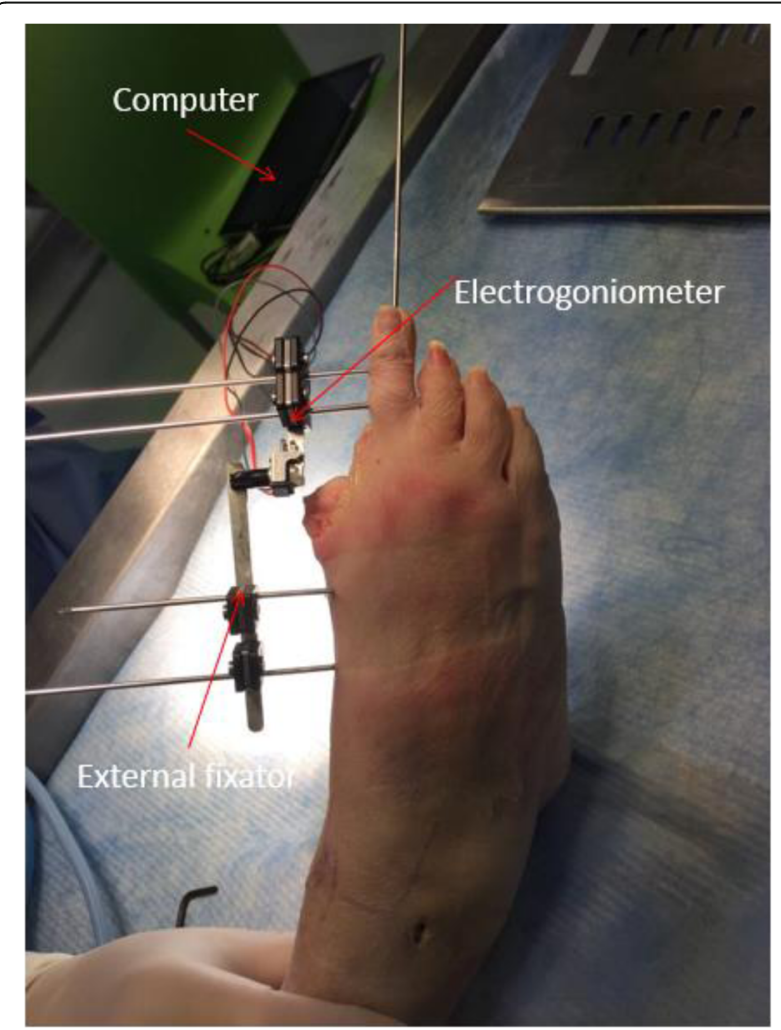

Fig. 11 Electro-goniometer for range of motion measurement
Metatarsal component in place). The phalangeal component is then screwed into the phalanx.

The trial liners are used to determine the size of the plastic bearing meniscus. Once the soft tissue is well balanced, the correct size polyethylene is inserted into place (Fig. 9 - Complete lesser metatarsophalangeal replacement in situ). Stability and range of motion is checked. The soft tissue is repaired and once again stability, alignment and range of motion are checked.

$\mathrm{X}$-ray facilities were available for two cadaver specimens (separate from the four cadavers that were tested) to simulate live surgery and obtain radiographs of the implant in the cadaver foot (Fig. 10 Radiographic appearance of the implant (antero-posterior and lateral views)). No measurements were performed hence there was no need to amputate the hallux.

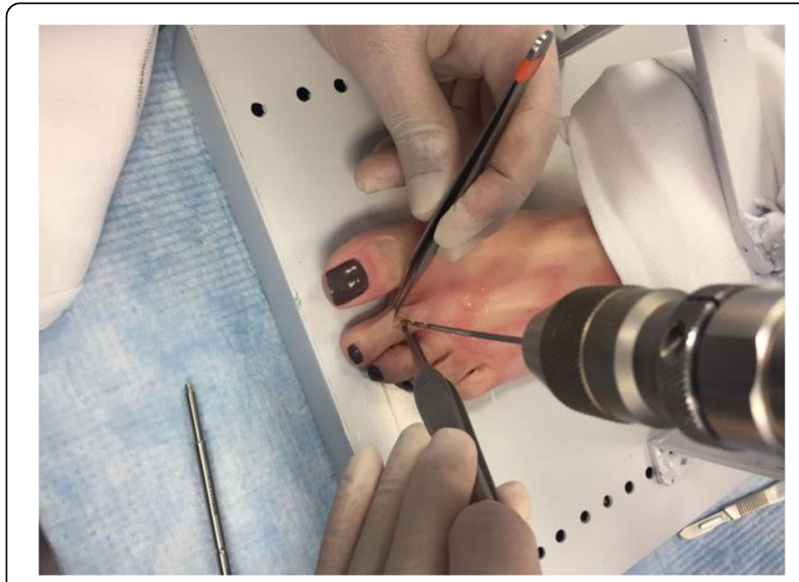

Fig. 12 Screw implanted in proximal phalanx for the purpose of stability testing 


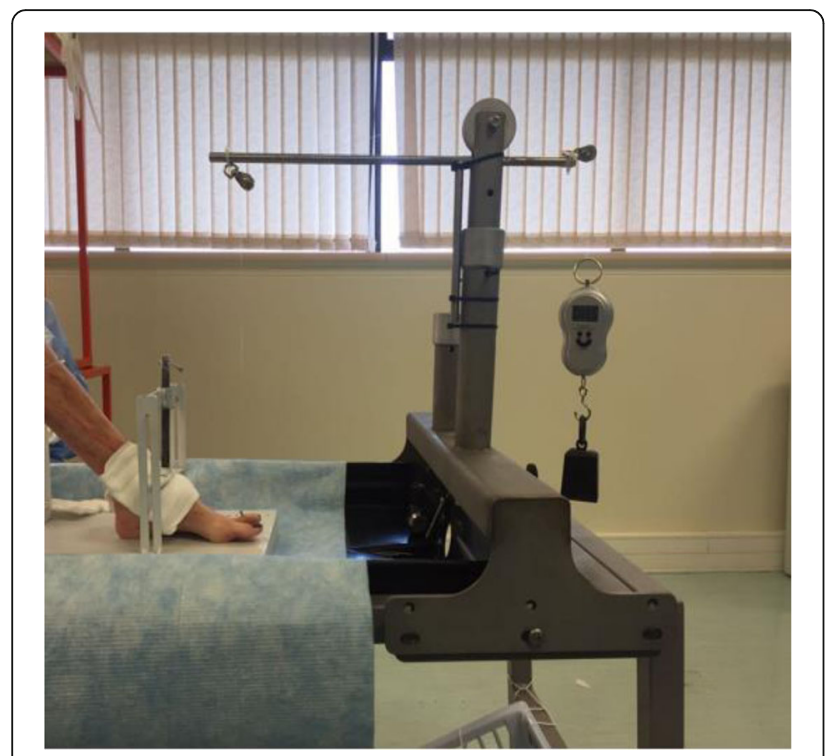

Fig. 13 Stability testing setup

\section{Range of motion measurements}

A custom-made electro-goniometer and open-source simulation software Ardino Software (IDE) was used (Fig. 11 - Electrogoniometer for range of motion measurement). Range of motion of the pre- and postimplanted LMTPJ was recorded. Prior to the measurement, the LMTPJ was taken through several cycles in order to reach a point of resistance by the same examiner.

\section{Stability}

Stability of the pre- and post-implanted joints was performed clinically with a drawer test as well as using a custom-made device. A screw implanted into the proximal phalanx was used for this purpose (Fig. 12 - Screw implanted in proximal phalanx for the purpose of

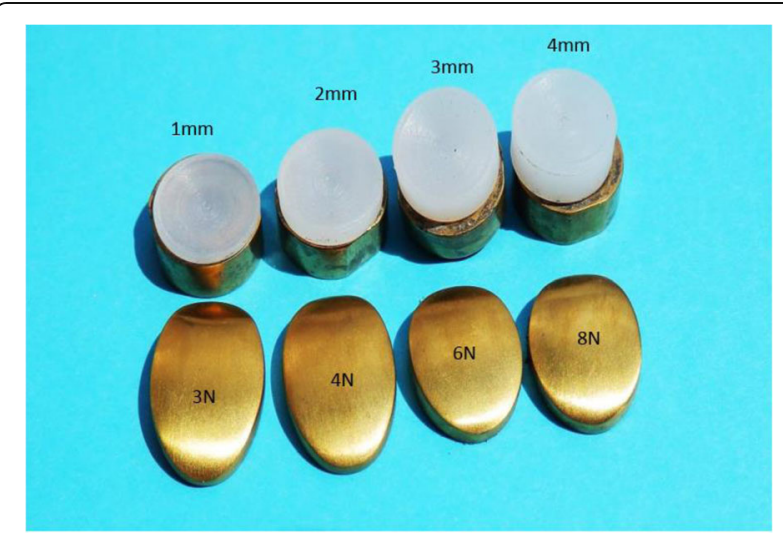

Fig. 14 The four implants each with the respective compressive forces as well as the sizes after completing 5,000,000 cycles at physiological forces
Table 1 Measurements pre and post endurance testing after 5,000,000 cycles at physiological forces

\begin{tabular}{lll}
\hline Implant size & Original thickness $(\mathbf{m m})$ & Final thickness $(\mathbf{m m})$ \\
\hline $1 \times 9 \mathrm{~mm}-3 \mathrm{~N}$ & 1.00 & 1.00 \\
$2 \times 9 \mathrm{~mm}-4 \mathrm{~N}$ & 2.00 & 2.00 \\
$3 \times 9 \mathrm{~mm}-6 \mathrm{~N}$ & 3.00 & 3.00 \\
$4 \times 9 \mathrm{~mm}-8 \mathrm{~N}$ & 4.00 & 4.00 \\
\hline
\end{tabular}

stability testing). In consultation with the engineers, the friction and friction losses through the set-up were found to be negligible.

A weight force of $5 \mathrm{~kg}(\mathrm{~F}=\mathrm{m} \mathrm{x}$ a) equalling $49 \mathrm{~N}$ was used. This force was shown on previous cadaveric studies to disrupt the soft tissue stabilizing factors of the LMTPJ and is thus seen as very conservative. On average the subluxation stability of the intact joints is around 25 $\mathrm{N}$ in a dorsal or superior direction and approximately $16 \mathrm{~N}$ in dorsiflexion [32, 33] (Fig. 13 - Stability testing setup).

\section{Results}

\section{Laboratory results}

From the photographic images captured after testing, it was clear that almost no sign of wear or surface deformation is visible on all four implants tested at the respective physiological compression forces (Fig. 14 - The four implants each with the respective compressive forces as well as the sizes after completing 5,000,000 cycles at physiological forces).

Moreover, the contact surfaces of all four titanium implants show no discolouring after 5 million cycles. Thickness measurements prior and after testing also showed no changes measured in micrometres (Table 1).

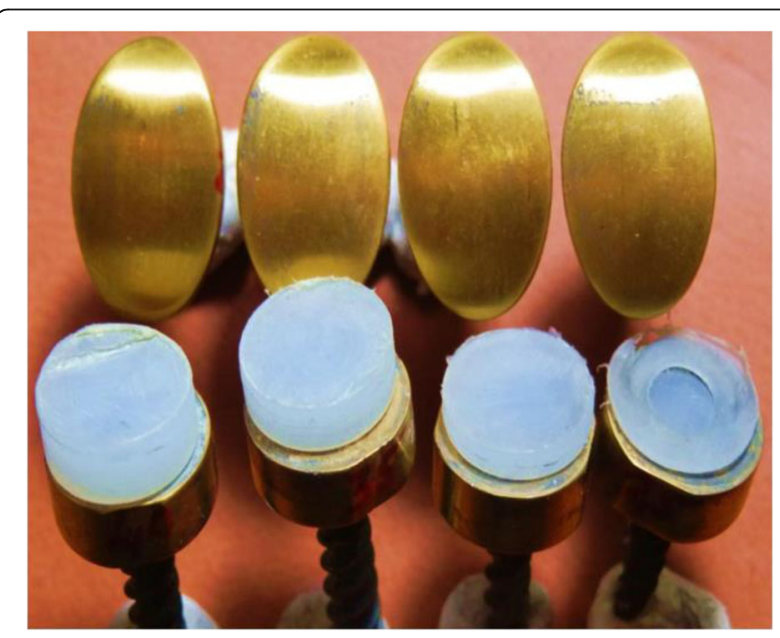

Fig. 15 Wear of contact surfaces post testing after 5,000,000 cycles at excessive forces 
Table 2 Measurements pre and post endurance testing after 5,000,000 cycles at excessive forces

\begin{tabular}{lll}
\hline Implant size & Original thickness $(\mathbf{m m})$ & Final thickness $(\mathbf{m m})$ \\
\hline $1 \times 9 \mathrm{~mm}-25 \mathrm{~N}$ & 1.00 & 0.45 \\
$2 \times 9 \mathrm{~mm}-30 \mathrm{~N}$ & 2.00 & 1.55 \\
$3 \times 9 \mathrm{~mm}-35 \mathrm{~N}$ & 3.00 & 2.55 \\
$4 \times 9 \mathrm{~mm}-40 \mathrm{~N}$ & 4.00 & 3.56 \\
\hline
\end{tabular}

No polyethylene particles were found in the de-ionized water.

Significant wear was evident on all four inserts after testing at excessive forces (Fig. 15 - Wear of contact surfaces post testing after 5,000,000 cycles at excessive forces).

Table 2 shows the measurements pre and post endurance testing.

\section{Cadaver result}

\section{Range of motion}

A total of four dorsiflexion and plantar flexion measurements were included in the study.

The LMTPJ dorsiflexion both pre- and post-implant varied widely from $12^{\circ}-52^{\circ}$ and $20^{\circ}-41^{\circ}$ respectively with an average of $28.5^{\circ}$ and $28.9^{\circ}$ respectively. The LMTPJ plantar flexion also varied widely from $22^{\circ}-$ $52^{\circ}$ and $8^{\circ}-35^{\circ}$ respectively with an average of $33.8^{\circ}$ and $20.8^{\circ}$ respectively (Table 3 ).

Table 3 shows that there was no significant difference in the average range of motion pre- and post- implant (note that a larger sample size could provide more clarity).

\section{Clinical stability}

Stability was divided into stable, lax and dislocatable. Besides the one pre-implant specimen which was lax, all the others were stable both pre- and post-implant. The lax pre implant joint most probably stabilized with the soft tissue balance achieved with the implant (size of meniscus) (Table 4).

\section{Stability with 5 kgf ( 49 N)}

All the specimens both pre- and post-implant were stable in dorsal displacement and dorsiflexion using a 5 kg weight $(49 \mathrm{~N})$ (Table 5).

\section{Discussion}

Lesser metatarsophalangeal joint arthritis (primarily Freiberg's infraction and post traumatic), may require surgical intervention once conservative management fails. There is poor evidence in supporting resection arthroplasty, excision interpositional arthroplasty, autografts and allografts [13-15]. To date there is no effective long-term replacement arthroplasty option. Silicone [17-26], ceramic [30] and metal LMTPJ arthroplasty $[27,28]$ have been reported with mixed success.

The use of silicone is associated with numerous complications $[3,34]$ including prosthetic loosening with failure, transfer lesions, local bone erosion, joint synovitis, infection secondary to impaired vascularity, lack of toe purchase with functional disability of the involved toe and foreign body reaction. As a result of the above problems, other materials such as titanium were introduced. Shih et al. described a case study using a titanium hemi-implant of the proximal phalanx. The benefit of this hemi-implant is that it does not alter the metatarsal parabola and allows for other surgical procedures to be performed in the future [28].

Total ceramic arthroplasty has been reported by Townshend and Greiss for painful, destructive disorders of the lesser MTPJs. All nine patients were female with a mean age of 51 years. The indications included primary and revision procedures. One case required a custom implant. Mean follow-up was 23 months with a mean AOFAS score of 75. Eight patients reported good or excellent results [30]. This was a small cohort with short follow-up.

Studies currently available are between case series and reports at level IV and V. The findings cannot be generalized or interpreted due to the low numbers, the retrospective nature of the studies and due to the rarity of the disease.

The idea of a total LMTPJ replacement arthroplasty remains a feasible option for the isolated arthritic LMTPJ. Although not subjected to large axial loads, these replacements still need to adhere to the basic principles of replacement implants and good soft tissue tension restoration to be successful. The available body of evidence around LMTPJ replacement arthroplasty comprises few studies of very small patient cohorts, and as such no grade of recommendation for

Table 3 Lesser metatarsophalangeal joint range of motion: pre and post implant

\begin{tabular}{|c|c|c|c|c|c|c|c|c|c|c|c|c|c|}
\hline \multirow[b]{2}{*}{ specimen } & \multicolumn{6}{|c|}{ Pre - implant } & \multicolumn{7}{|c|}{ Post implant } \\
\hline & 1 & 2 & 3 & 4 & Mean (SD) & $95 \% \mathrm{Cl}$ & 1 & 2 & 3 & 4 & Mean (SD) & $95 \% \mathrm{Cl}$ & $p$-value \\
\hline DORSIFLEXION (degrees) & 12,34 & 12,65 & 52,5 & 31,6 & $33.78(12.74)$ & $13.51-54.05$ & 21,89 & 20,15 & 32,48 & 40,95 & $19.84(11.78)$ & $0.78-38.91$ & 0.1619 \\
\hline PLANTAR FLEXION (degrees) & 28,66 & 22,02 & 32,75 & 51,75 & $27.27(19.08)$ & $3.09-57.63$ & 12,32 & 28,45 & 8,1 & 34,5 & $26.62(12.52)$ & $6.70-38.91$ & 0.9561 \\
\hline
\end{tabular}


Table 4 Lesser metatarsophalangeal joint stability clinically: pre and post implant

\begin{tabular}{|c|c|c|c|c|c|c|}
\hline & \multicolumn{3}{|c|}{ Pre-implant } & \multicolumn{3}{|c|}{ Post-implant } \\
\hline & Stable & Lax & Dislocatable & Stable & Lax & Dislocatable \\
\hline 1 & $\cdot$ & & & $\cdot$ & & \\
\hline 2 & $\cdot$ & & & $\cdot$ & & \\
\hline 3 & & $\cdot$ & & $\cdot$ & & \\
\hline 4 & . & & & . & & \\
\hline
\end{tabular}

any particular procedure or implant can be made with confidence [35].

For these reasons the author developed this LMTPJ replacement. The materials used in this implant (titanium and UHMWPE) are accepted internationally and the titanium nitride is proven to enhance surface hardness. The sizes of the metallic components (metatarsal and phalangeal) were determined by the accurate measurement of the respective bones on skeleton specimens. The metatarsal component fixation mechanism is unique. It has a "spring" intra medullary fixation mechanism with added "barbs" to increase the surface area. The mobile bearing is likewise unique in its attachment to the phalangeal component in that it is a completely rotating platform which allows a certain amount of multidirectional gliding and a wide range of motion. The phalangeal fixation is of the screw in type.

The implant is not a substitute for a poorly functioning or unbalanced ray in the forefoot. Large contact area is achieved between the component and the subchondral bone by virtue of the flat resection of the bone and the flat surface of the component.

The implant alone is by no means the stabilizing factor. Soft tissue balancing and fibrous tissue surrounding the implant provide the majority of strength to support the joint.

Cyclical loading of 5,000,000 cycles within physiological forces showed minimal wear of both the metatarsal implant and polyethylene meniscus.

The in vitro cadaveric studies allowed the researchers to develop and perfect the surgical technique, record the range of motion, determine the stability both clinically and by means of applied forces. The authors noted the large discrepancies in the range of motion pre and post- implant in some of the specimens and this was attributed to the quality of tissue in the cadaver. Nevertheless, the range of motion was maintained and even slightly improved in some of the specimens. The stability was excellent in both dorsal displacement and dorsiflexion.

There are few cadaveric studies pertaining to general loading and forces on the LMTPJ and there are no available cadaveric studies for LMTPJ replacement arthroplasty. Often implants in the development phase lack cadaveric trials and are only subjected to cyclical loading followed by clinical trials.

The relatively large bearing surfaces between the components will hopefully contribute to the longevity of the replacement arthroplasty but this will remain to be seen. In the event of implant failure with no possibility of a revision, the implant can be removed and the joint left as an "excision arthroplasty" which although not ideal has been described as a surgical option for Freiberg's infraction or degenerative joint disease.

Considering published articles regarding cadaver utilization, this research presents an in vitro study which utilized 15 cadavers, culminating in six cadavers in the final stages (four for technique and measurement testing and two for assessment of surgical technique and X-rays by an independent foot and ankle surgeon).

\section{Conclusion}

This novel LMTPJ replacement arthroplasty has been developed to fill the void of replacement arthroplasty options in the isolated arthritic LMTPJ. This novel threecomponent implant has high conformance and a large bearing surface. Cyclic loading of the implants under physiological loads has shown no signs of wear or damage.

This proof of concept study has shown this LMTPJ replacement to be simple in its surgical technique requiring minimal specialized instrumentation, achieving good range of motion and stability, albeit the inferior quality of cadaveric tissue, with good surgical reproducibility. This study is the basis for clinical trials (the implant has been cleared for clinical trials by Human Ethics of the University). For clinical trials, as with other replacements, the "ideal" candidate must be sought, followed by the stringent principles of replacements and informed consent.

Table 5 Lesser metatarsophalangeal joint stability with $5 \mathrm{kgf}(49 \mathrm{~N})$ pre and post implant

\begin{tabular}{|c|c|c|c|c|c|c|c|c|c|c|c|c|}
\hline & \multicolumn{6}{|c|}{ Pre-implant } & \multicolumn{6}{|c|}{ Post-implant } \\
\hline & \multicolumn{3}{|c|}{ Dorsal displacement } & \multicolumn{3}{|c|}{ Dorsiflexion } & \multicolumn{3}{|c|}{ Dorsal displacement } & \multicolumn{3}{|c|}{ Dorsiflexion } \\
\hline & Stable & Lax & Dislocatable & Stable & Lax & Dislocatable & Stable & Lax & Dislocatable & Stable & Lax & Dislocatable \\
\hline 1 & $\cdot$ & & & $\cdot$ & & & $\cdot$ & & & $\cdot$ & & \\
\hline 2 & $\cdot$ & & & $\cdot$ & & & · & & & $\cdot$ & & \\
\hline 3 & $\cdot$ & & & · & & & · & & & $\cdot$ & & \\
\hline 4 & . & & & - & & & . & & & . & & \\
\hline
\end{tabular}




\section{Abbreviations}

LMTPJ: Lesser metatarsophalangeal joint; MTPJ: Metatarsophalangeal joint: UHMWPE: Ultra-high molecular weight polyethylene

\section{Acknowledgements}

Not applicable

\section{Authors' contributions}

Each author personally and significantly contributed towards the development of this article: NPS: Conceived and planned the activities that led to the study, executed the testing and cadaver trials, wrote the paper and approved the final version. PNFF: Participated in the cadaver trials, interpreted the results of the study and participated in the reviewing process. AS: Participated in the reviewing process and the cadaver trials. All authors have read and approved the manuscript.

\section{Authors' information}

Investigations were performed at the Smith and Nephew cadaver laboratory in Durban, Kwa Zulu Natal, the Arthrex cadaver laboratory in Cape Town and the Council for Scientific and Industrial Research (CSIR), Pretoria, South Africa. The paper was presented at the "A World Advanced Foot and Ankle Congress" (webinar) on 25-26 April 2020 (by invitation).

The article is part of a PhD dissertation at the University of the

Witwatersrand, Johannesburg, South Africa.

Date of successful thesis defense: 30/3/2019.

\section{Funding}

The implant was manufactured free of charge by Southern Medical (SA). The cadavers were supplied by Smith \& Nephew (SA). The Laboratory apparatus and testing equipment were self funded by NPS.

\section{Availability of data and materials}

Please contact author for data requests.

\section{Declarations}

\section{Ethics approval and consent to participate}

Ethics approval for this study was obtained from the Wits Human Research Ethics Committee. All Cadaver parts were donated for research purposes Protocol number M180380 Ref: W-CJ-140813-1 (13-08-2014).

\section{Consent for publication}

Not Applicable.

\section{Competing interests}

The authors declare that they have no competing interests. Each author certifies that he has no commercial associations that might pose a conflict of interest in connection with the submitted article.

\section{Author details}

${ }^{1} T$ The Orthopaedic Foot and Ankle Unit, Suite 303 Netcare Linksfield Hospital, 24 12th Avenue, Linksfield West, Johannesburg 2192, South Africa. ${ }^{2}$ Foot and Ankle Unit, Division of Orthopaedic Surgery, University of the Witwatersrand, Johannesburg, South Africa. ${ }^{3}$ Netcare Sunninghill Hospital, Suite 3A, -2 Level, Westwing, Cnr Nanyuki \& Witkoppen Road, Sunninghill, Johannesburg 2157, South Africa.

\section{Received: 29 December 2020 Accepted: 13 April 2021} Published online: 07 May 2021

\section{References}

1. el-Tayeby HM. Freiberg's infraction: a new surgical procedure. J Foot Ankle Surg. 1998;37(1):23-7. https://doi.org/10.1016/S1067-2516(98)80007-0.

2. Lavery L, Harkless LJTJ. The interpositional arthroplasty procedure in treatment of degenerative arthritis of the second metatarsophalangeal joint. J Foot Surg. 1992;31 (6):590-4.

3. Carmont MR, Rees RJ, Blundell CM. Current concepts review: Freiberg's disease. Foot Ankle Int. 2009;30(2):167-76. https://doi.org/10.3113/FAl-20090167.
4. Enriquez Castro JA, Guevara Hernandez G, Estevez DG. Interposition arthroplasty as treatment of osteochondritis of the second metatarsal head. A case report. Acta Ortop Mex. 2008;22(4):259-62.

5. Lee EJ, Wong YS. Modification of lesser metatarsophalangeal joint arthroplasty using flexor digitorum longus transfer. Foot Ankle Spec. 2008; 1(2):85-7. https://doi.org/10.1177/1938640008315348.

6. Lui TH. Arthroscopic interpositional arthroplasty for Freiberg's disease. Knee Surg Sports Traumatol Arthrosc. 2007;15(5):555-9. https://doi.org/10.1007/ s00167-006-0189-4.

7. Lui TH. Arthroscopic interpositional arthroplasty of the second metatarsophalangeal joint. Arthrosc Tech. 2016;5(6):e1333-e8. https://doi. org/10.1016/j.eats.2016.08.008.

8. Myerson M. Reconstructive foot and ankle surgery. Philadelphia: Elsevier Saunders; 2005.

9. Myerson MS, Kadakia AR. Reconstructive foot and ankle surgery: management of complications: Ebook. Elsevier Health Sciences; 2018.

10. Özkan Y, Ozturk A, Özdemir R, Aykut S, Yalçin N. Interpositional arthroplasty with extensor digitorum brevis tendon in Freiberg's disease: a new surgical technique. Foot Ankle Int. 2008;29(5):488-92. https://doi.org/10.3113/FAl.2 008.0488 .

11. Thompson FM, Hamilton WG. Problems of the second metatarsophalangeal joint. Orthopedics. 1987;10(1):83-9. https://doi.org/10.3928/0147-7447-1 9870101-15.

12. Zgonis T, Jolly GP, Kanuck DM. Interpositional free tendon graft for lesser metatarsophalangeal joint arthropathy. J Foot Ankle Surg. 2005;44(6):490-2. https://doi.org/10.1053/j.jfas.2005.08.005.

13. Stautberg EF III, Klein SE, McCormick JJ, Salter A, Johnson JE. Outcome of lesser metatarsophalangeal joint interpositional arthroplasty with tendon allograft. Foot Ankle Int. 2020:41(3):313-9. https://doi.org/10.1177/107110072 0904033.

14. Abdul W, Hickey B, Ferera A. Functional outcomes of local pedicle interpositional arthroplasty in adults with severe Freiberg's disease. Foot Ankle Int. 2018;39(11):1290-300. https://doi.org/10.1177/10711 00718786494

15. Liao C-Y, Lin AC-C, Lin C-Y, Chao T-K, Lu T-C, Lee H-M. Interpositional arthroplasty with palmaris longus tendon graft for osteonecrosis of the second metatarsal head: a case report. J Foot Ankle Surg. 2015;54(2):237-41. https://doi.org/10.1053/j.jfas.2014.12.003.

16. Hill J, Jimenez AL, Langford JH. Osteochondritis dissecans treated by joint replacement. J Am Podiatry Assoc. 1979;69(9):556-61. https://doi.org/10.754 7/87507315-69-9-556.

17. Cracchiolo A III, Kitaoka HB, Leventen EO. Silicone implant arthroplasty for second metatarsophalangeal joint disorders with and without hallux valgus deformities. Foot Ankle Int. 1988;9(1):10-8. https://doi.org/10.1177/10711 0078800900104

18. Lawrence BR, Papier MJ. Implant arthroplasty of the lesser metatarsophalangeal joint - a modified technique. J Foot Surg. 1980;19(1): $16-8$.

19. Miller ML, Lenet MD, Sherman M. Surgical treatment of Freiberg's infraction with the use of total joint replacement arthroplasty. J Foot Surg. 1984;23(1): $35-40$.

20. Scartozzi G, Schram A, Janigian J. Freiberg's infraction of the second metatarsal head with formation of multiple loose bodies. J Foot Surg. 1989; 28(3):195-9.

21. Sgarlato T. A new implant for the metatarsophalangeal joint. Clin Podiatry. 1984;1(1):69-77.

22. Sgarlato TE. Sutter double-stem silicone implant arthroplasty of the lesser metatarsophalangeal joints. J Foot Surg. 1989;28(5):410-3.

23. Teich LJ, Frankel JP, Lipsman S. Silicone hinge replacement arthroplasty. J Am Podiatry Assoc. 1981;71(5):266-72. https://doi.org/10.7547/87507315-715-266.

24. Tintocallis CA. Nicolle finger joint prosthesis: a preliminary study of total joint replacement for lesser metatarsophalangeal joints. J Foot Surg. 1982; 21(1):57-60.

25. Freed JB. Alternative approaches to replacement of lesser metatarsal heads. J Foot Surg. 1979;18(1):26-30.

26. Pfeiffer WH, Cracchiolo A 3rd, Grace DL, Dorey FJ, Van Dyke E. Double-stem silicone implant arthroplasty of all metatarsophalangeal joints in patients with rheumatoid arthritis. Semin Arthroplasty. 1992;3(1):16-24.

27. Feinblatt JS, Smith WB. Lesser Metatarsal Metallic Hemiarthroplasty. Techniques in Foot \& Ankle Surgery. 2014;13(4):199-205. 
28. Shih AT, Quint RE, Armstrong DG, Nixon BP. Treatment of Freiberg's infraction with the titanium hemi-implant. J Am Podiatr Med Assoc. 2004; 94(6):590-3. https://doi.org/10.7547/0940590.

29. Feinblatt JS, Smith WB. Lesser metatarsal metallic hemiarthroplasty. Techinques Foot Ankle Surg. 2014;13(4):199-205. https://doi.org/10.1097/ BTF.0000000000000065.

30. Townshend DN, Greiss ME. Total ceramic arthroplasty for painful, destructive disorders of the lesser metatarsophalangeal joints. Foot. 2007;17(2):73-5. https://doi.org/10.1016/j.foot.2006.09.006.

31. Betts RP, Franks Cl, Duckworth T. Analysis of pressures and loads under the foot. Part 2: quantification of the dynamic distribution. J Clin Physiol Meas. 1989;1:113.

32. Chalayon O, Chertman C, Guss AD, Saltzman CL, Nickisch F, Bachus KN. Role of plantar plate and surgical reconstruction techniques on static stability of lesser metatarsophalangeal joints: a biomechanical study. Foot Ankle Int. 2013;34(10):1436-42. https://doi.org/10.1177/1071100713491728.

33. Suero EM, Meyers KN, Bohne WHO. Stability of the metatarsophalangeal joint of the lesser toes: a cadaveric study. J Orthopaedic Res Ens. 2012; 30(12):1995-8. https://doi.org/10.1002/jor.22173.

34. Cerrato RA. Freiberg's disease. Foot Ankle Clin. 2011;16(4):647-58. https:// doi.org/10.1016/j.fcl.2011.08.008.

35. Wright JG, Einhorn TA, Heckman JD. Grades of recommendation. J Bone Joint Surg Am. 2005;87(9):1909-10. https://doi.org/10.2106/00004623-2 00509000-00001.

\section{Publisher's Note}

Springer Nature remains neutral with regard to jurisdictional claims in published maps and institutional affiliations.

Ready to submit your research? Choose BMC and benefit from:

- fast, convenient online submission

- thorough peer review by experienced researchers in your field

- rapid publication on acceptance

- support for research data, including large and complex data types

- gold Open Access which fosters wider collaboration and increased citations

- maximum visibility for your research: over $100 \mathrm{M}$ website views per year

At $\mathrm{BMC}$, research is always in progress.

Learn more biomedcentral.com/submissions 